An An Asian Journal of Soil Science

A Case Study

DOI : 10.15740/HAS/AJSS/12.2/355-360

\title{
Sustainable soil fertility management for horticultural crops
}

\section{NAGAHARSHITHA AND KUNAL GAIKWAD}

MEMBERS OF RESEARCH FORUM:

Corresponding author :

D. NAGAHARSHITHA, Sri Konda

Laxman Telangana State

Horticultural University,

Rajendranagar, HYDERABAD

(TELANGANA) INDIA

Email: harshi.dmg@gmail.com

Co-authors :

KUNAL GAIKWAD, Dr. Panjabrao

Deshmukh Krishi Vidyapeeth, AKOLA (M.S.) INDIA
Received : 09.09.2017; Accepted : 30.11.2017

\section{Summary}

India is bestowed with varied soil conditions, which is highly favourable for growing a large number of horticultural crops from tropical to temperate; seasonal to perennial ensuring good returns throughout the year. The farming community of the country has efficiently exploited this natural endowment (Siddiqui et al., 2014). Excessive application of nutrients has the harmful impacts on soil physical, chemical and biological system which are the pillars of soil fertility resulting in several socio-economic and environmental concerns. Further, the food and nutritional security of ever increasing population in the scenario of changing climate, decreasing arable land for production indicates the attention of holistic soil fertility management approach for sustainable production of horticultural crops. Relevant indices of sustainable horticulture and resource management include soil quality and resilience and factors affecting them and temporal changes in productivity and use efficiency of non-renewable or input of limited resources (Lal, 2008) which there by helps in sustainability productivity of horticultural crops.

Key words : Soil fertility, Management, Horticultural crops

How to cite this article : Nagaharshitha, D. and Gaikwad, Kunal (2017). Sustainable soil fertility management for horticultural crops. Asian J. Soil Sci., 12 (2) : 355-360 : DOI : 10.15740/HAS/AJSS/ 12.2/355-360. 